\title{
The Utilization of Alpha-1 Anti-trypsin (A1AT) in Infectious Disease Monitoring and Treatment
}

\author{
Irene L. Indalao, Agustiningsih Agustiningsih, Eka Pratiwi, Kartika Dewi Puspa, Hartanti Dian Ikawati, \\ Ririn Ramadhany
}

Center for Research and Development of Biomedical and Basic Technology of Health, National Institute of Health Research and Development, Ministry of Health Republic of Indonesia

\begin{abstract}
Alpha one anti-trypsin (A1AT) is a major serine protease inhibitor found circulating in human blood. A1AT related studies mainly focus on A1AT potential biomarker as well as therapeutic target in non-infectious diseases. Their findings indicate A1AT beneficial features may also be applied for monitoring and treating infectious disease. However, only a few studies have reviewed A1AT's useful properties as a biomarker and therapeutic agent for infectious diseases. This narrative review aims to summarize growing evidences that support the idea of utilizing A1AT as a tool for monitoring and therapy for infectious diseases.

A1AT showed potential as a biomarker for a wide spectrum of infectious disease, from virus, bacteria, to parasite. Its level and functionality were proposed to predict risk for disease susceptibility or progression and to indicate response therapy. As promising therapeutic agent in various infectious diseases, the administration of A1AT has shown antimicrobial activity, immunomodulatory and anti-apoptotic effect, in addition to more familiar function, suppressing excessive proteolysis.

The broad utilization of A1AT, both as biomarker and therapeutic agent, in studies on infectious diseases seems promising. However, there are issues need to be investigated further before establishing its feasibility as a monitoring and therapy tool against infection diseases. J Microbiol Infect Dis 2019; 9(1): 51-58.
\end{abstract}

Keywords: Alpha-1 anti-trypsin, virus, bacteria, biomarker, drug, infection, parasite, protozoa, review

\section{INTRODUCTION}

Alpha one antitrypsin (A1AT) belongs to serine protease inhibitor superfamily. It is synthesized in the endoplasmic reticulum of hepatocytes, bronchial and type II alveolar epithelial and endothelial cells and secreted into the circulation system, lung lavage, interstitium of the lung and body fluids such as saliva, tears, breast milk, urine, and semen [1,2]. The rise of A1AT level above normal level (plasma: 20-53 mM, interstitial fluid 10-40 mM, epithelial lining fluid (ELF) 2-5 mM) signifies a pathological condition [3]. In normal condition, the lung produces an enzyme such as elastase to ensure that it is free from pollutants or pathogens. However, due to its proteolytic activity, elastase can be dangerous as it can breakdown lung structures if not regulated properly [4]. The main role of the
A1AT is to maintain lung integrity and function as the principal inhibitor of elastase [5].

SERPINA1 is the gene that regulates A1AT expression. The mutation of this gene results in defective A1AT. The most common mutation forms are $Z$ type A1AT, and the milder form, $S$ type A1AT [6,7]. The $Z$ type mutation prevents A1AT to mature and form secretion especially in liver and lung. The $S$ type is an unstable protein with shortened serum half-life [8]. Another rarely found mutation, the null mutation, abolishes A1AT production [9]. People with such mutation have higher risk of developing lung and liver disease [8-9].

The roles of A1AT have been studied and reviewed extensively in non-infectious disease settings. The reviews highlight beneficial effect of A1AT in treating cystic fibrosis (CF), chronic

Correspondence: Dr. Irene L. Indalao, Pusat Penelitian dan Pengembangan Biomedis dan Teknologi Dasar Kesehatan, Badan Penelitian dan Pengembangan Kesehatan, Kementerian Kesehatan Republik Indonesia, Jakarta Pusat, Indonesia 
obstructive pulmonary disease (COPD), collagen induced arthritis (CIA), graft versus host disease (GVHD), diabetes, acute myocardial infarction, inflammatory bowel disease, acute liver failure, and cancer [2,7,1012]. The therapeutic effects of augmenting A1AT observed in these studies include suppressing pro-inflammatory cytokines, reducing inflammatory cell infiltration, increasing antiinflammatory cytokines, and reducing apoptosis. Whether A1AT has similar potential against infectious disease has not been reviewed yet. In this review, we aim to identify studies emphasize A1AT as a useful tool for monitoring and therapy for infectious diseases, and to recommend future research to be considered before implementing A1AT utilization into practice. The findings emphasize A1AT beneficial features that can be applied for infectious disease management are summarized in Table 1 and Table 2.

\section{A1AT utilization as a biomarker to predict susceptibility and disease progression of certain infection}

A1AT has been proposed as a risk biomarker for certain infection since in its deficient state, one becomes more susceptible to infection. This has been indicated by Acquired Immunodeficiency Syndrome (AIDS) studies in which patients with A1AT deficiency had higher risk to get infected by HIV compared to healthy control [13-16]. Furthermore, study presented evidence that A1AT level in Bronchoalveolar Lvage Fluid (BALF) could be a predictive factor for HIV infected patients to develop emphysema [17]. It showed a high level of A1AT serum in HIV patients with A1AT deficient condition predisposes them to the development of emphysema. The analysis revealed that circulating protein could not function as well as its normal form [17]. This finding suggests the term of "deficiency" in this context does not only refer to the amount of A1AT in the host but also the functionality of this inhibitor.

Another study observed similar potential in Mycobacterium abscessus infection. The abnormal A1AT phenotype predisposes patients to develop non tuberculous mycobacterium infection (NTBI) [18]. The potential use of A1AT to predict someone's susceptibility to HIV and NTBI opens the possibility that A1AT could be used to predict susceptibility to other infectious diseases in which its pathogen entry or release depends on host protease activation and whether its level can be used to predict progression of the infection.

The rise of A1AT level in the A1AT non deficient infected person compared to healthy control indicate an acute phase infection, as shown in the case of Dengue virus, Mycobacterium tuberculosis, Mycobacterium abscessus, and malaria infection [19-28,31,43-44]. Moreover, the fall inA1AT level may reflect the response after the therapy. A study in Uganda exhibited TB (tuberculosis) patients initially had a high level of A1AT in their sera. By the end of either standard TB therapy (rifampin, isoniazid, pyrazinamide, and ethambutol) or experimental therapy (rifapentine used as substitute to rifampin), the level of A1AT serum in the recovering patients' sera had decreased [25]. While A1AT is not the only acute phase reactant measured and known to decrease after successful treatment, the finding shows A1AT is useful to monitor patient response to TB therapy.

Many studies have investigated whether A1AT can be utilized as a biomarker to determine the severity level of the infection of dengue fever (DF) and malaria. One of them found high A1AT and NS1 proteins in the sera of all of DF and dengue hemorrhagic fever (DHF) patients, while only lower level seen in healthy controls [19]. Other study, however, did not observe significant change of A1AT level in non-severe dengue and severe dengue infection [26]. This indicates it is less effective to use A1AT as biomarker to predict the dengue severity. Meanwhile, a research group incubated synthetic hemozoin, a protein secreted by Plasmodium falciparum during hemolysis into circulation, within the sera of malaria patients and healthy controls and analyzed serum proteins that bind with the hemozoin. They found A1AT as one of the major hemozoin binding proteins identified only in malaria patient samples [27]. Therefore, the interaction of host and pathogen protein may support A1AT as a malaria biomarker. Although it is still not clear whether the fold increase of A1AT can give information of severity degree of malaria 
infection, their data showed a trend that severe malaria has higher A1AT level than the mild one.

\section{A1AT utilization as a therapeutic agent to overcome infection}

The antiviral properties of A1AT have been attributed to its ability to bind and inactivate the virus fusion protein. A study demonstrated Virus Inhibitor Peptide (VIRIP), the most potent fraction of A1AT, inhibits HIV gp41 fusion peptide that disrupts HIV entry [28]. This finding was supported by other group's work where they nominated $\mathrm{C}$-terminus of $\mathrm{A} 1 \mathrm{AT}$ as an essential function domain mediates the inhibition of HIV entry by interacting with gp41 [29].

Another antiviral property of A1AT is its ability to bind and inhibit some host proteases used by the viruses to cleave their proteases to ensure their replication and spread within the host cells. The $\mathrm{F}$ protein of Measles virus cleaves host protease furin. Using human glioma cells which stably expressing constructed A1AT, Alpha-1Antitrypsin Portland (Alpha1-PDX), A1AT was demonstrated toinhibit F0 cleavage by furin, resulting in significant reduction of infectious virus titers [30]. HCMV (Human cytomegalovirus) infection has been displayed to be inhibited in a similar way. Utilizing Alpha-1PDX, furin was completely blocked, preventing the maturation of HCMV envelope protein called glycoprotein $\mathrm{B}(\mathrm{gB})$ and dramatically reducing infectious HCMV in vitro [31]. Furthermore, Lassa virus precursor glycoprotein, preGP-C, was found to be recognized and subsequently cleaved by the host protease, S1P (sphingosine 1 phosphate). By constructing A1AT to imitate S1P recognition motives owned by Lassa virus glycoprotein, they demonstrated that A1AT intervene the proteolytic activation of Lassa virus preGP-C by S1P. As a consequence, the virus maturation cannot proceed, making the released noninfectious virions in vitro [32, 33].

Meanwhile, the interaction between A1AT and Human Rhinovirus (HRV) seems to be unique. Instead of binding and inactivating HRV $3 \mathrm{C}$ protease, which involves in HRV replication and maturation, A1AT suppresses HRV host receptor gene expression, namely, intercellular adhesion molecule-1 (ICAM-1) (). In turn, A1AT treatment on infected brushed bronchial epithelial cell culture reduces viral load [34].
Moreover, A1AT administration has been proven to suppress the inflammation factors such as IL8 in infected brushed bronchial epithelial cells and its homolog in mouse, KC (keratinocyte chemoattractant) in wild type C57BL/6 mice [35].

A1AT also has antibacterial ability. A1AT provides protection to human alveolar epithelial cell type II and mouse lung from Pseudomonas aeruginosa invasion and subsequent inflammation [36]. The study corroborates with other that discovered aerosolized purified human A1AT treatment significantly suppressed lung inflammation and advanced bacterial clearance in rat [37]. Furthermore, A1AT prevents short palate, lung, and nasal epithelium clone 1 (SPLUNC1) from being degraded by neutrophil elastase, preventing the infected mice from losing their antimicrobial proteins [38]. These studies propose A1AT protective effect is due to its ability to inhibit neutrophil elastase which not only prevent the host from extreme increase of inflammatory cytokines but also helps the host maintains its cell membrane integrity. Interestingly, there was a study showed that Pseudomonas aeruginosa also produces elastase which can potentially inactivate A1AT before it makes a complex with trypsin or neutrophil elastase [39-41]. However, their findings have not been confirmed in the cell culture and animal studies. Another study investigated the potential of A1AT in supressing Mycobacterium abscessus infection in human macrophages. A1AT could block rapidly growing mycobacterium (RGM) uptake by monocytes derived from healthy human peripheral blood mononuculear cells (PBMC) [18]. A potential therapy of A1AT for patients with sustained growing mycobacteria pulmonary disease was proposed.

In Escherichia coli (E. coli) infection, the use of A1AT as therapeutic agent seems promising. Using in vitro system, a study showed A1AT can bind with Escherichia coli protein EspB, inhibiting it from integrating with host cell membrane and subsequent bacteria protein invasion into cell cytosol, hence, preventing hemolysis [42]. In vivo, A1AT administration to purified lipopolysaccharide derived from E.coli (LPS) induced acute lung injury mice results in decreased LPS induced inflammation. The similar finding was shown in human lung 
microvascular endothelial cell system. The unique property of $A 1 A T$ found in this study is that the anti-inflammatory effective was not due to the usual neutrophil elastase inhibition activity but from suppression of factors related to endoplasmic reticulum stress pathway [43]. Another demonstrated tissue protective effect of A1AT was in accordance with reduced bacterial burden infection in mouse model [44].

A1AT treatment also has also been proposed to counteract the infection of Moraxella catarrhalis, a gram negative bacteria causing acute otitis and respiratory tract infection in human. A study revealed A1AT anti-inflammatory effect that is independent from A1AT proteolytic activity in purified tonsillar B cell culture [45] since both active and inactive form of $\mathrm{A} 1 \mathrm{AT}$, could inhibit MID-induced tonsillar B cell proliferation and IL-6 release. Unfortunately, there has not been updated study exploring A1AT effect upon Moraxella catarrhalis yet since this report.

The A1AT potential against parasite infection also described in previous studies $[46,47]$. They focused on Cryptosporidum parvum, a parasite causing diarrhea in human and severe morbidity in immune-compromised host. Its spread through oocysts phase, which can stand wide range of environmental exposure, highlights the importance to eradicate its oocysts. In earlier study, they found A1AT can be used as anticryptosporidiosis when A1AT gains access into Cryptosporodium parvum oocyst and prevent its excystation in vitro [46]. On the other hand, A1AT inhibition activity is less effective against its sporozoite phase. To overcome this issue, they combined the human A1AT treatment with paromomycin and obtained more promising result in their subsequent study [47].

Altogether, these studies provide evidences to support the idea of proposing human A1AT as an alternative infectious disease treatment in non-deficient setting. They also imply administration of A1AT may help A1AT deficient infected patients to counteract the damage caused by the infection.

Table 1. Use of A1AT in viral infections.

\begin{tabular}{ll}
\hline Infectious & A1AT utilization \\
Pathogen &
\end{tabular}

Virus

Biomarker

Therapeutic Agent [Ref No]

\begin{tabular}{|c|c|c|}
\hline HIV & $\begin{array}{l}\text { low level in serum precedes HIV infection; deficient patient has higher } \\
\text { risk to get infected by HIV [13-16]; high level in serum but deficient in } \\
\text { terms of function predisposes HIV patients with emphysema } \\
\text { development [17] }\end{array}$ & $\begin{array}{c}\text { inhibits VIRIP to cleave } \\
\text { with gp41 }[28,29]\end{array}$ \\
\hline Rhinovirus & no reference available yet & $\begin{array}{l}\text { inhibits HRV receptor } \\
\text { induction [34] and anti } \\
\text { inflammatory [35] }\end{array}$ \\
\hline
\end{tabular}
high level indicates acute phase infection [19;20,21]; higher level in DF
Dengue virus $\quad$ and DHF cases compared to healthy control. A trend of higher level as no reference available yet
the severity degree increases but not significant [26]

\section{Lassa virus}

Measles no reference available yet
Human
cytomegalovirus

inhibits S1P to activate Lassa's preGP-C $[32,33]$

inhibits furin to cleave Measles F protein [30]

nhibits furin to cleave virus maturation protein, gB 


\begin{tabular}{|c|c|c|c|}
\hline \multirow{2}{*}{$\begin{array}{l}\text { Infectious } \\
\text { Pathogen } \\
\text { Bacteria }\end{array}$} & \multicolumn{2}{|c|}{ A1 AT utilization } & \multirow[b]{2}{*}{ Note } \\
\hline & Biomarker & $\begin{array}{c}\text { Therapeutic Agent [Ref } \\
\text { No] }\end{array}$ & \\
\hline Escherichia coli & no reference available yet & $\begin{array}{l}\text { anti-inflammatory [42,44], } \\
\text { prevents tissue damage } \\
\text { [44], inhibits hemolysis [42] }\end{array}$ & \\
\hline
\end{tabular}

$\begin{aligned} & \text { Mycobacterium } \\ & \text { abscessus }\end{aligned}$ predispose patient to develop NTBI [18] bacteria reduction [18]

$\begin{array}{lcl}\text { Mycobacterium } & \text { increase in TB patients compared to control } \\ \text { tuberculosis } & \text { participant [22];decline at the end of TB no reference available yet } \\ \text { therapy and burden disease [25] }\end{array}$

\section{Pseudomonas aeruginosa}

\section{Moraxella catarrhalis}

Legionella pneumophila

Serratia

marcessens

Yersinia

enterocolitica

Staphylococcus

aureus

Parasites

no reference available yet anti-inflammatory [36-38] and prevents tissue damage [36]
A1AT is inhibited by elastase, but in certain condition [39-41]

\section{full length active or inactive \\ A1AT can suppress}

inflammation [45] 
Most studied therapeutic feature of A1AT has been its ability to counteract and block the activity of certain proteases secreted as a response to remove infectious pathogens, which at the same time; can dissociate the cell membranes integrity, resulting in structural damage. Second, it interacts directly with certain host pathogen receptors or pathogen's structural protein. The availability and functionality of A1AT will interfere and inhibit the interaction between the pathogen and the host factors.

This is usually applicable to microorganisms whose entry or release needs activation of host proteases and the outcome can affect their infectivity. Third, the A1AT can modulate inflammation in several ways; suppressing the pro-inflammatory cytokines and chemokines, activating the increase production of antiinflammatory cytokines, suppressing factors of endoplasmic reticulum stress pathway. In a particular case, A1AT can inhibit the microorganism life stage development directly, such as preventing oocyst excystation. Implications for future research and studies exploiting A1AT for infectious disease management.

The evidences that A1AT can be useful to indicate acute phase infection of various microorganisms are accumulating. While this can be advantageous, it cannot be used to identify specific pathogen, considering A1AT level change was found not only in one infection. On the other hand, A1AT level alteration can be used to describe the disease stage the patient is in. Thus, its level measurement may become practical in monitoring treatment response. Additionally, measuring A1AT level may be recommended to predict the risk of patients to be susceptible to certain infection or disease progression.

Despite promising preliminary evidences of using A1AT to counteract infection, it may seem sensible to nominate A1AT as alternative for infectious disease treatment. However, it is important to cautiously calculate its feasibility. Not all A1AT beneficial effect during infection has been verified in nonhuman primate or human model. Also, there are proteases secreted by the infectious pathogens able to inactivate A1AT protease activity like Tissue Destructive Protease (TDP) secreted by
Legionella pneumophila and Staphylococcus aureus' proteinase (STAP) [37,48]. They inactivate A1AT only if the binding site of A1AT has not been occupied by host's serine protease. Additionally, Serratia marcescens' metalloprotease can degrade A1AT [49]. Meanwhile, Trichomonas vaginalis binds to A1AT and uses it as protection from harmful effect secreted by host fluid or leukocytes [50]. Other study reported Yersinia enterocolitica outer protein (YopM) has a specific binding site for A1AT, but the biological function of their interaction has not been clarified [51]. These findings suggest; A1AT may not be suitable for treating all infectious diseases. Researchers should comprehend the pathogenesis of the pathogen before considering A1AT as potential drug. Another issue needs clarification is whether additional A1AT will compromise the host ability to clear the pathogen, since it will suppress the elastase production. Lastly, we recommend future studies should investigate whether A1AT therapy can be advantageous in co-infection settings.

\section{Conclusion}

In the future, public health and clinical practitioners may benefit from harnessing beneficial features of A1AT, considering the recent growing indications that $A 1 A T$ can be utilized as a biomarker and therapeutic agent for particular infectious diseases. Nevertheless, further investigations, especially for drug development, are needed to prevent any adverse event for the patient.

\section{ACKNOWLEDGMENTS}

We would like to thank Ni Ketut Susilarini, Vivi Setiawaty, and Dorothy Southern for their valuable suggestions in developing this manuscript.

Declaration of Conflicting Interests: The authors declare that they have no conflict of interest.

Funding statement: The current work received no external funds.

\section{REFERENCES}

1. Gooptu B, Ekeowa UI, Lomas DA. Mechanisms of emphysema in alpha1-antitrypsin deficiency: molecular and cellular insights. Eur Respir J 2009; $34(2): 475-88$. 
2. Lussier B, Wilson AA. Alpha-1 Antitrypsin. In: Wanner A, Sandhaus RS, editors. Alpha-1 Antitrypsin, Switzerland: Springer International Publishing; 2016, p. $17-30$

3. McElvaney NG. Alpha-1 antitrypsin therapy in cystic fibrosis and the lung disease associated with alpha-1 antitrypsin deficiency. Ann Am Thorac Soc 2016; 13(6):S191-S196.

4. Korkmaz B, Poutrain P, Hazouard E, De Monte M, Attucci S, Gauthier FL. Competition between elastase and related proteases from human neutrophil for binding to a1-protease inhibitor. Am J Respir Cell Mol Biol 2005; 32(6):553-559.

5. Serban KA, Petrache I. Alpha-1 antitrypsin and lung cell apoptosis. Ann Am Thorac Soc 2016;13 (Supplement 2):S146-149.

6. Hurley K, Reeves EP, Carroll TP, McElvaney NG. Tumor necrosis factor- $\alpha$ driven inflammation in alpha-1 antitrypsin deficiency: a new model of pathogenesis and treatment. Expert Rev Respir Med 2015; 6348:1-16.

7. Janciauskiene $S$, Welte T. Well-known and less well-known functions of Alpha-1 antitrypsin: Its role in chronic obstructive pulmonary disease and other disease developments. Ann Am Thorac Soc 2016; 13:S280-S288.

8. Chiuchiolo MJ, Crystal RG. Gene therapy for alpha-1 antitrypsin deficiency lung disease. Ann Am Thorac Soc 2016; 13:S352-S369.

9. McElvaney NG. Diagnosing a1-antitrypsin deficiency: How to improve the current algorithm. Eur Respir Rev 2015; 24(135):52-57.

10. Lewis EC. Expanding the Clinical Indications for a1-Antitrypsin Therapy. Mol Med 2012; 18(6):957970.

11. Brebner JA, Stockley RA. Recent advances in $\alpha$ 1-antitrypsin deficiency-related lung disease. Expert Rev Respir Med 2013; 7(3):213-230.

12. Guttman O, Baranovski BM, Schuster R, et al. Acute-phase protein alpha1-anti-trypsin: Diverting injurious innate and adaptive immune responses from non-authentic threats. Clin Exp Immunol 2015;179(2):161-172.

13. Hayes VM, Gardiner-Garden M. Are polymorphic markers within the alpha-1-antitrypsin gene associated with risk of human immunodeficiency virus disease? J Infect Dis 2003; 188(8):1205-1208.

14. Adedeji AL, Olawoye TL. Elevated Serum Alpha1-Antitrypsin Concentration is Associated with HIV Disease Non-Progression. MOJ Immunol 2015; 2(3):1-5

15. Ferreira TC da S, Sampaio EP, Argañaraz GA, Gondim MVP, Shapiro L, Argañaraz ER. Increased prevalence of the alpha-1-antitrypsin (A1AT) deficiency-related $S$ gene in patients infected with human immunodeficiency virus type 1. J Med Virol 2014; 86(1):23-29.

16. Bryan CL, Beard KS, Pott GB, Rahkola J, Gardner EM, Janoff EN SL. HIV infection is associated with reduced serum alpha-1-antitrypsin concentrations. Clin Invest Med 2010; 33(6):E384-389.

17. Stephenson SE, Wilson CL, Crothers K, et al Impact of HIV Infection on Alpha-1Antitrypsin in the Lung. Am J Physiol Lung Cell Mol Physiol 2018; 314(4):L583-L592.

18. Chan ED, Iseman MD. Alpha-1-antitrypsin (AAT) anomalies are associated with lung disease due to rapidly growing mycobacteria and AAT inhibits Mycobavteriuim abscessus infection of macrophages. Scand J Infect Dis. 2007;39:690-6.

19. Thayan R, Huat TL, See LLC, et al. The use of two-dimension electrophoresis to identify serum biomarkers from patients with dengue haemorrhagic fever. Trans R Soc Trop Med Hyg 2009;103 (4):413419.

20. Kumar Y, Liang C, Bo Z, Rajapakse JC, Ooi EE, Tannenbaum SR. Serum Proteome and Cytokine Analysis in a Longitudinal Cohort of Adults with Primary Dengue Infection Reveals Predictive Markers of DHF 2012; 6(11):e1887.

21. Jadhav $M$, Nayak $M$, Kumar $S$, et al. Clinical Proteomics and Cytokine Profiling for Dengue Fever Disease Severity Biomarkers. Omi A J Integr Biol 2017; 21 (11):665-677.

22. Song SH, Han M, Choi YS, et al. Proteomic profiling of serum from patients with tuberculosis. Ann Lab Med 2014; 34(5):345-353.

23. Ray $S$, Renu D, Srivastava R, et al. Proteomic investigation of falciparum and vivax malaria for identification of surrogate protein markers. PLoS One 2012; 7(8):e41751.

24. Ray S, Patel SK, Venkatesh A, et al. Quantitative Proteomics Analysis of Plasmodium vivax Induced Alterations in Human Serum during the Acute and Convalescent Phases of Infection. Sci Rep 2017; 7(1):4400.

25. De Groote MA, Nahid P, Jarlsberg L, et al. Elucidating Novel Serum Biomarkers Associated with Pulmonary Tuberculosis Treatment. PLoS One 2013; 8(4):e61002.

26. Soundravally $R$, Agieshkumar B, Daisy $M$, Sherin J, Cleetus CC. Ferritin levels predict severe dengue. Infection 2015; 43(1):13-19.

27. Kassa FA, Shio MT, Bellemare MJ, Faye B, Ndao $M$, Olivier $M$. New inflammation-related biomarkers during malaria infection. PLoS One 2011; 6(10):e26495.

28. Munch J, Ständker L, Adermann K, et al. Discovery and Optimization of a Natural HIV-1 Entry Inhibitor Targeting the gp41 Fusion Peptide. Cell 2007; 129(2):263-275. 
29. Zhou X, Liu Z, Zhang J, Adelsberger JW, Yang $\mathrm{J}$, Burton GF. Alpha-1-antitrypsin interacts with gp41 to block HIV-1 entry into CD4+ T lymphocytes. BMC Microbiol 2016; 16(1):172.

30. Watanabe M, Hirano A, Stenglein S, Nelson J, Thomas G, Wong TC. Engineered serine protease inhibitor prevents furin-catalyzed activation of the fusion glycoprotein and production of infectious Measles virus. J Virol 1995; 69(5):3206-3210.

31. Jean F, Thomas L, Molloy SS, et al. A proteinbased therapeutic for Human cytomegalovirus infection. Proc Natl Acad Sci 2000; 97(6): 2864-2869.

32. Lenz O, ter Meulen J, Klenk HD, Seidah NG, Garten W. The Lassa virus glycoprotein precursor GP-C is proteolytically processed by subtilase SKI1/S1P. Proc Natl Acad Sci U S A 2001; 98(22):1270112705.

33 Maisa A, Ströher U, Klenk HD, Garten W, Strecker T. Inhibition of Lassa virus glycoprotein cleavage and multicycle replication by site 1 proteaseadapted a1- antitrypsin variants. PLoS Negl Trop Dis 2009; 3(6):e446.

34. Berman $R$, Jiang $D$, Wu $Q$, Chu HW. a1Antitrypsin reduces Rhinovirus infection in primary human airway epithelial cells exposed to cigarette smoke. Int J Chron Obstruct Pulmon Dis. 2016; 11(1):1279-1286.

35. Jiang $D$, Berman $R$, Wu $Q$, Stevenson $C$, Chu HW. The Anti-inflammatory Effect of Alpha-1 Antitrypsin in Rhinovirus-infected human airway epithelial cells. J Clin Cell Immunol 2016; 7(6):1-17.

36. Pott GB, Beard KS, Bryan CL, Merrick DT, Shapiro L. Alpha-1 Antitrypsin Reduces Severity of Pseudomonas Pneumonia in Mice and Inhibits Epithelial Barrier Disruption and Pseudomonas Invasion of Respiratory Epithelial Cells. Front Public Heal 2013; 1:19.

37. Cantin AM, Woods DE. Proliferation in a Model of Chronic Pseudomonas aeruginosa Lung Infection. Am J Respir Crt Care Med. 1999; 160(19):1130-1135.

38. Jiang D, Persinger R, Wu Q, Gross A, Chu HW. a1-antitrypsin promotes SPLUNC1-mediated lung defense against Pseudomonas aeruginosa infection in mice. Respir Res 2013; 14:122.

39. Morihara K, Tsuzuki H, Oda K. Protease and Elastase of Pseudomonas aeruginosa: Inactivation of Human Plasma a1-Proteinase Inhibitor. Infect Immun 1979; 24(1):188-193.

40. Sponer $M$, Nick $H$, Schnebli $H$. Different Susceptibility of Elastaase Inhibitors to Inactivation by Proteinases from Staphylococcuus aureus and Pseudomonas aeruginosa. Biol Chem 1991; 372:963970.

41. Padrines M, Bieth JG. Pseudomonas aerugionsa Elastase Does Not Inactivate a1-Proteinase Inhibitor in the Presence of Leukocyte Elastase. Infect Immun 1989; 57(12):3793-3797

42 Knappstein S, Ide T, Schmidt MA, et al. a 1 Antitrypsin Binds to and Interferes with Functionality of EspB from Atypical and Typical Enteropathogenic Escherichia coli Strains. Infect Immun 2004; 72(8):4344-4350.

43. Jonigk $\mathrm{D}, \mathrm{Al}$-Omari $\mathrm{M}$, Maegel $\mathrm{L}$, et al. Antiinflammatory and immunomodulatory properties of a1-antitrypsin without inhibition of elastase. Proc Natl Acad Sci 2013; 110(37):15007-15012.

44. Kaner Z, Ochayon DE, Shahaf G, et al. Acute phase protein $\alpha 1$-antitrypsin reduces the bacterial burden in mice by selective modulation of innate cell responses. J Infect Dis 2015; 211(9):1489-1498.

45. Hadzic R, Nita I, Tassidis H, Riesbeck K, Wingren AG, Janciauskiene S. a1-Antitrypsin inhibits Moraxella catarrhalis MID protein-induced tonsillar B cell proliferation and IL-6 release. Immunol Lett 2006; 102(2):141-147.

46. Forney JR, Yang S, Healey MC. Antagonistic Effect of Human Alpha-1-Antitrypsin on Excystation of Cryptosporidium parvum Oocysts. J Parasitol 1996; 83(4):771-774

47. Forney JR, Yang S, Healey MC. Synergistic anticryptosporidial potential of the combination alpha1- antitrypsin and paromomycin. Antimicrob Agents Chemother 1997; 41(9):2006-2008.

48. Conlan JW, Williams A AE. Inactivation of Human $\alpha$-1-Antitrypsin by a Tissue-destructive Protease of Legionella pneumophila. J Gen Microbiol 1988;134:481-487.

49. Molla A, Matsumoto K, Oyamada I, Katsuki T $\mathrm{MH}$. Degradation of Protease Inhibitors, Immunoglobulins, and Other Serum Proteins by Serratia Protease and Its Toxicity to Fibroblasts in Culture. Infect Immun 1986; 53(3):522-529.

50. Peterson KM, Alderete JF. Acquisition of aLAntitrypsin by a Pathogenic Strain of Trichomonas vaginalis. Infect Immun 1983; 40(2):640-46.

51. Heusipp G, Spekker K, Brast S, Fälker S, Schmidt MA. YopM of Yersinia enterocolitica specifically interacts with a1-antitrypsin without affecting the anti-protease activity. Microbiology 2006; 152(5):1327-1335. 